\title{
Report on the impact of cultural diversity in simulation for nursing students engaged in immersion experiences in global settings
}

\author{
Christy Seckman, Holly J. Diesel \\ Goldfarb School of Nursing at Barnes-J ewish College, St. Louis, MO, USA \\ Correspondence: Christy Seckman. Address: Goldfarb School of Nursing at Barnes-J ewish College, St. Louis, MO, USA. \\ Email: Cseckman@bjc.org.
}

Received: September 27, 2012

Accepted: December 23, 2012

Online Published: February 25, 2013

DOI : $10.5430 /$ jnep.v3n9p30

URL: http://dx.doi.org/10.5430/jnep.v3n9p30

\section{Abstract}

Nursing students in the US are under increasing pressure to be equipped with appropriate knowledge and skills to meet an increasingly diverse American population. In order to meet this challenge, The American Association of Colleges of Nursing has charged nursing educators to incorporate cultural competence into nursing curriculums. Simulation scenarios focusing on assessment, including communication with clients from diverse cultures is a method to help students begin to practice safe nursing in a controlled environment. Nursing students in a baccalaureate program in the Midwest participated in scenarios designed to heighten their awareness of clues in the environment in order to interact with clients from different cultural backgrounds. The scenarios provided artifacts such as items of clothing, prayer rug, and statues that were consistent with specific cultures and helped direct the students to identify the need for an interpreter. Eighteen senior level students in the BSN program enrolled in an elective as part of an immersion experience in countries outside of the US. These students gained a better appreciation of the importance of obtaining culturally appropriate assessments in order to provide culturally competent care as evidenced by comments in their reflective journals.

\section{I ntroduction}

The population in the United States has become ever more diverse since the 1990's as evidenced by the report from the US Department of State which predicts that US minorities will be the majority by $2042^{[1]}$. Segments of the minority population experience health disparities and receive a lower quality of health care services ${ }^{[2,3]}$. For example, in 2005, although African American women were $10 \%$ less likely to have to have been diagnosed with breast cancer, they were $34 \%$ more likely to die from breast cancer when compared to non-Hispanic white women. Hispanic males have three times the AIDS rate as non Hispanic males, and American Indian children are $30 \%$ more likely to be diagnosed with asthma ${ }^{[4]}$. While the US population shifts more toward the global face where 75 out of 100 people correspond to non-white ethnicity, this trend is not seen in the nursing profession. Currently, the predominately female registered nursing workforce is comprised of $83.2 \%$ non-Hispanic Whites ${ }^{[5]}$. In an attempt to address these differences, nursing education programs have begun to incorporate cultural competency components into the curriculum and to include cultural competency as a program outcome. Ideally, a diverse faculty could also enhance understandings of diverse populations, but until this occurs improved cultural awareness must be provided by the curricula itself. 
Both the American Nurses Association (ANA) and the International Council of Nurses (ICN) Code of Ethics include statements that require nurses to incorporate culture into all the domains of nursing practice and ethical care ${ }^{[6,7]}$. Responding to clients with appropriate cultural sensitivity is an essential competency for all nurses, and one that takes both education and practice to achieve. Many approaches have been used including activities, programs and service learning projects, cultural immersion both domestic and abroad, and free standing courses. Simulation is one educational format that helps to ensure that nursing students are both competent and confident in the delivery of culturally competent care. Simulation is also the precursor to real life encounters with culturally diverse patients in non-domestic settings. The aims of this article are to examine the concepts of teaching cultural competency through high fidelity human patient simulation, and to demonstrate how those simulation situations increased student confidence in delivering culturally competent care during immersion experiences.

\subsection{Diversity and cultural competence}

With increasing cultural diversity within our society, nursing students often find the challenge of engaging with a client who appears different and holds different cultural beliefs to be overwhelming. This is common, considering that nearly 90 percent of the nursing workforce defines themselves as Caucasian ${ }^{[2]}$ and 91 percent are female ${ }^{[4]}$, while the clients they care for are increasingly likely to be from a different culture or ethnic group. Culture consists of everything we know and understand about a group of people and includes the way they live, how they communicate and how they view the world. Cultures reflect patterns of human thoughts, beliefs, values, and customs. Culture shapes how people relate to one another. Culture also influences the way nurses deliver care as well as how the clients respond to that care. Leininger ${ }^{[8]}$ coined the term cultural competency and is credited with promoting its use among transcultural nurses.

Campinha-Bacote's framework ${ }^{[9]}$ further describes cultural competence as a progression through a series of sequential stages. Initially, the nursing student must develop a deeper understanding of self and others, which requires that they recognize their own ethnocentrism and develop a willingness to learn about other world views, and cultural differences and similarities ${ }^{[9]}$. The next stage is the acquisition of cultural health knowledge which incorporates the health beliefs and practices, including disease prevalence and preferred treatments ${ }^{[9]}$. Cultural skill refers to the opportunity to practice collecting holistic data relevant to the client's concerns. The nursing student is then ready to engage in the cross cultural encounter where they begin to develop real world experience. Finally and arguably the most important, nursing students must possess the cultural desire or the motivation to want to work with diverse populations ${ }^{[9]}$. Cultural competency does not mean that the student must abandon their own identity, but rather be willing to respectfully accept that there are many ways to view the world, and walk with a foot in two worlds.

\subsection{Nursing code of ethics}

The ANA states that, "Knowledge of cultural diversity is vital at all levels of nursing practice" ${ }^{[6]}$. Cultural knowledge and its impact on health care are essential for nurses, regardless of where they practice or where they are in their career trajectory, which includes the novice student nurse. Nurses bring both their personal cultural heritage and their cultural and philosophical views of their education into the professional setting. Therefore, it is important for the nurse to understand that nurse-client encounters include the interaction of three cultural systems: the culture of the nurse, the culture of the client and the culture of the setting. The ICN further states that "inherent in nursing is respect for human rights, including the right to life, to dignity and to be treated with respect. Nursing care is unrestricted by considerations of age, color, creed, culture, disability or illness, gender, nationality, politics, race or social status” ${ }^{\text {[7] }}$.

\subsection{Simulation}

Nurse educators working as classroom, lab and clinical instructors can recall too many situations when observing students looking into the face of others different from themselves seemed particularly challenging. Nursing students must develop the ability to recognize cultural diversity, integrate cultural knowledge, and act in a culturally appropriate manner. This skill set enables student nurses to be more effective in initiating nursing assessments and serving as client advocates. In order for nursing students to acquire this skill set, all nursing curricula must include information regarding diverse health 
care beliefs, values, and practices. Educational programs must demonstrate to nursing students that cultural beliefs and practices are as integral to the nursing process as the acquisition of psychomotor skills and the interpretation of physical and psycho-social factors.

Simulation has been used in health care education since the 1960's when Rescue Anne was incorporated into resuscitation training ${ }^{[10]}$. As the nursing role began to evolve with the increasing complexity of clients, nurses were challenged to learn new skills. Simulation seemed to be the answer. Jeffries ${ }^{[11]}$ states simulation offers health care educators a tool that can be used repeatedly by learners in a safe and protected environment. Nursing is a practice-based discipline and with the use of simulation student outcomes will improve without causing harm to the clients. Through simulation, "students are able to experience caring for diverse populations; they are taught to recognize diversity, commonalities, and the blending of cultures as many clients have dual-citizenship, increased geographical movement, and better education than was seen previously"[12].

According to Vardi ${ }^{[13]}$, learning in a simulated environment requires rigorous planning, good teaching skills, and an evaluation process that supports the learning objectives of the simulation experience. In the planning phase of a simulation learning objectives are developed, also the tasks and activities required of the students for the simulation are identified. Good teaching skills focus on learning through doing, the student performs the scenario according to the established criteria in order to improve their skills. Attention is given to student's needs and styles of learning. Managing the simulation session well allows for students to complete all tasks and activities. Once the simulation session has concluded, evaluation of the student experience is needed in order to determine what went well and how to improve. Learning in the simulated environment often takes the faculty back to the beginning to plan, execute, and to continue re-evaluating the experience for the students.

Currently, there is still a need for standards and guidelines for the application of simulation techniques to learning and assessment environments ${ }^{[14]}$. These guidelines and best-practice methods would be beneficial when applying simulation to healthcare education. Eventual development of a standard template with common objectives, terminology, curricular format, outcomes and assessment tools is strongly indicated for the use of simulation ${ }^{[15]}$.

Simulation scenarios are preparation for actual encounters which allow the student to make mistakes and experiment with alternative responses in a safe setting. In this case study, immersion experiences provided the students with opportunities to use skills and knowledge they had learned in simulation towards real life encounters in foreign settings with diverse populations.

\subsection{I mmersion}

Many schools of nursing incorporate service-learning into their curricula, with the majority of projects in community health courses, while a few others have utilized either domestic or international immersion experiences. Immersion provides an excellent pedagogy for introducing students to clients of different cultural backgrounds. Immersion helps nursing students to become aware of the issues clients face related to culture and health care, as well teaching culturally appropriate care with opportunities to practice in vivo. Research has demonstrated that nursing students who are involved in an international immersion experience garner many benefits including increased cultural sensitivity, improved self confidence and increased communication skills ${ }^{[14-16]}$. Immersion experiences also affect many other factors, including the emotional, intellectual, personal and professional growth of the nursing students. In this case study, immersion in an unfamiliar setting was used as a format to apply the skills and knowledge of cultures used in simulation to an actual patient encounter.

\section{Case presentation}

A culturally diverse simulation was developed in a health assessment course in order to expose students to an environment of diverse cultures prior to progressing to the hospital setting. The goal of this scenario was to have student's demonstrate 
competency in identifying that their client was culturally different from them, identify the culture of the client, and call an interpreter for assistance in order to obtain the client's a blood pressure.

It was decided to use an Arabic interpreter for convenience purposes, as that particular interpreter was readily available and willing to participate in the simulation exercise. The Arabic interpreter prerecorded client responses for the mannequin before the simulation exercise began. Students were pre-briefed with the information that a blood pressure was needed on this particular client, English was not spoken by the client, and an interpreter would be needed to accomplish this task. Students were directed to use the phone in the lab to contact interpreter services for assistance.

\section{Setting the stage}

The simulation environment was staged with artifacts to emulate those that would be consistent with a client of Arabic heritage. Identifying artifacts included a prayer rug, prayer beads in the mannequin's hand, Hijab on her head, an amulet hanging from the mannequin's neck, and hospital information package at the bedside identifying the Arabic language.

Accelerated nursing students in their first semester performed the scenario. The students were placed in groups of three and entered the lab. They identified themselves as nursing students to the client and attempted to tell the client that they needed to obtain a blood pressure. Once it was established that this client did not speak English, one of the nursing students used the telephone to call for interpreter services. This number rang in the control booth of the simulation lab and simulation staff answered. The student had to request an Arabic interpreter to come to the simulation lab. Once the interpreter arrived, the interpreter introduced herself to the client and explained what the nursing students wanted to do. Clarification was given to the client in Arabic and the interpreter kept the students informed of the client's concerns. Once the client's blood pressure was successfully obtained, the scenario was terminated. A debriefing session followed.

\section{Discussion}

The students who participated in this scenario were pre briefed in order to have some knowledge of the simulation experience. Even though students were told that the client would not be able to understand or speak English, students began to laugh, appeared anxious and nervous once they realized they did not understand the client. With several groups of students, it took several minutes before it was decided that they needed an interpreter. Students would continue talking to the client in English and receive communication they did not understand. During the call to interpreter services, several groups did not know the culture/language of the client even though it was clearly printed on the hospital information package and the presence of Arabic artifacts. Students had difficulty communicating to interpreter services the location of the client. This could be due to the scenario being performed in a lab versus a client's room. Once the interpreter arrived, the student's appeared less anxious and stressed. Professionalism developed with the interpreter where before the interpreter arrived on the scene, a less than professional environment existed. Students appeared in a confused state with nervous laughter. The interpreter told the Arabic women that the one of the nursing students would take her blood pressure by putting on the cuff and listening with a stethoscope. The mannequin responded positively and the student was able to assess the blood pressure. The scenario concluded at this point.

During the faculty led debriefing session, student's were asked "how they felt" during this exercise. Responses ranged from confusion to a total loss of what to do when the client spoke a different language from their own. Students stated they did not understand what the client was saying. Students described having feelings of anxiety and frustration. One student reported that her mind went blank to everything when she realized the client did not speak English. Students described calling interpreter services to be harder than they thought it would be. They felt they were not prepared to answer what language interpreter was needed nor where to direct the interpreter to go. These issues were discussed and students determined their anxiety of the situation contributed to their confusion. Students stated "they felt awkward in the client's room while waiting for the interpreter". Faculty suggested to the students to remove themselves from the client's room if they are uncomfortable while waiting for the interpreter as the client may feel uncomfortable as well. Students made side 
comments to each other during the scenario. It was suggested that the client may feel vulnerable in this type of situation. It may appear the students are talking about the client in a negative manner. When asked if the artifacts helped in determining the culture of the client, many students did not notice the presence of the relics. This could be due to inattentional blindness. The students were focused on what they considered a consuming task. They failed to notice the unexpected stimuli appearing in one's visual field, which is termed inattentional blindness. The interpreter discussed general cultural differences of the Arabic population with students so an understanding and growth of knowledge would occur. Students concluded that this was a good simulation as it would be applicable in their nursing practice.

\section{Application of skills in immersion settings}

As part of the international nursing program, a number of pre-licensure students participated in immersion experiences. These immersion experiences took the students to Cameroon, West Africa, Honduras, Finland and Swaziland. All of the students had participated in the health assessment course which included the simulation scenario on cultural assessment and sensitivity. The students were also exposed to additional information regarding cultural competency in a sensitivity training session to better prepare them for the differences they would experience in human beliefs and behaviors during their travels outside of the United States. These sessions covered a wide variety of topics. The topics included but were not limited to verbal and nonverbal communication pattern, relationships between genders, appropriate clothing, and food practices.

Prior to leaving for the immersion experience, all students were concerned about their ability to communicate effectively and respectfully. One student commented, "Even after all the reading and preparation, I am still so afraid I will say or do something that will offend someone". Other students felt that the term cultural competence was so over used it had little meaning, and one student said, "There is so much to learn. How does anyone ever become culturally competent in a culture that is not yours?” Another student worried that “using stereotypes is not the way I want to go. Ultimately, I need to treat every person I meet as an individual, rather than as general member of any given culture”. Students began to recognize that many of their beliefs were not based on evidence and that in fact, they did not know even themselves very well. Fortunately, they were all eager to learn and the upcoming immersion provided adequate incentive for them to do so.

Once the pre-trip jitters were over, and the students found themselves fully immersed, they began to appreciate just how much they did know, and how they were prepared to be open and flexible to the situation at hand. A student who had never left her home state previously said, "I see now that all my worries were silly. We really were prepared. The scenario opened our eyes. Just realizing that I can’t know it all, has made me much more accepting and relaxed when I meet a new situation or a new client who is very different from me. I understand that her clothing means something special, and how she communicates can't be interpreted using the same criteria I use with my friends. It is ok to not know, but it isn't ok to assume you know". Another student said, "The most important thing I picked up in the simulations was that it is ok to ask the simple or stupid question. I think it shows the other person that I really care about getting it right when I ask them to help me understand”. Multiple students identified the overall learning that took place during the simulation scenarios focusing on culture. One student in Honduras said, "All the cues and clues are there if you just take a few extra moments to really see what is in front of you. Then you can fill in the blanks with the help of the patient you are caring for, and really make a good plan that they can accept and that will be based on cultural evidence and the patient’s beliefs”.

The students and faculty recognize that even multiple scenarios focusing on cultural awareness or sensitivity will not be sufficient to achieve mastery in cultural competence. All immersion experience participants stressed the need for a variety of teaching methods that would help nursing students gain greater understanding of how to work with and care for clients who are different from themselves. Although lectures and reading assignments are an acceptable place to begin gaining knowledge, simulation provides the students with real time opportunities to practice using the information they have learned in a controlled and safe environment. 


\section{Conclusion}

Simulation can provide nursing students with opportunities to learn and practice skills that will benefit themselves and prepare them to provide high quality care within the culturally diverse global community. Nursing students gain confidence in their abilities while they develop confidence in delivering new skills in a safe setting. These assessment and communication skills will help them to benefit from the learning opportunities that arise when the students are working with clients different from themselves in both domestic and foreign locations. Introducing nursing students to values and beliefs that are relevant to the client populations they will work with helps them to see the role that culture plays in health care practices and decisions. Students then can better see health issues from a perspective different from their own which may help them to provide more culturally congruent care. In addition, the professional and person knowledge gained from both simulation and immersion will support them in becoming leaders in their profession

\section{Acknowledgement}

The authors would like to acknowledge the faculty and staff of Goldfarb School of Nursing at Barnes-Jewish College, and the students who participated in the immersion experiences to Cameroon, Swaziland, Honduras and Finland.

\section{References}

[1] United States Census Bureau. Available from: http://quickfacts.census.gov/qfd/states/00000.html. (21 August 2012).

[2] Lowe J, Archibal, C. Cultural diversity: The intention of nursing. Nursing Forum. 2009; 44: 11-18. PMid:19187049 http://dx.doi.org/10.1111/j.1744-6198.2009.00122.x

[3] U.S. Department of Health and Human Services. National Committee of Vital and Health Statistics Report: Eliminating health disparities: Strengthening data on race, ethnicity, language in the U.S. Washington, DC: Author. (10 September, 2012)

[4] Department of Health and Human Services, Office of Minority Health. Available from: http://minorityhealth.hhs.gov. (21 August 2012).

[5] Health Resources and Services Administration [HRSA]. The registered nurse population: Initial findings from the 2008 National Sample Survey of registered nurses. Washington DC: U. S. Department of Human Services. (10 September 2012)

[6] American Nurses Association. Available from: http://nursingworld.org (21 August 2012).

[7] International Council of Nurses. Available from: http://www.icn.ch/about-icn/code-of-ethics-for-nurses/code-of-ethics-for-nurses. (21 August 2012).

[8] Leininger, M. Culture care theory, research and practice. Nurs Sci Quart. 1995; 9(2): 71-74. http://dx.doi.org/10.1177/089431849600900208

[9] Campinha-Bacote, J. Inventory for assessing the process of cultural competence among healthcare professionals-revised. Retrieved August 21, 2010. Available from: www.transculturalcare.net/iapcc-r.htm

[10] Cooper JB, Taqueti VR. A brief history of the development of mannequin simulators for clinical education and training. Quality \& Safety in Health Care. 2004; 13: 11-17. PMid:19103813 http://dx.doi.org/10.1136/qshc.2004.009886

[11] Jeffries, P. Simulation in nursing education: From conceptualization to evaluation. Philadelphia, PA: Lippincott Williams \& Wilken, 2007.

[12] Hass B, Seckman C, Rea G. Incorporating cultural diversity and caring through simulation in a baccalaureate nursing program. Journal of Human Caring. 2010; 14(2): 50-51.

[13] Vardi, I. (2008). Teaching and learning through the simulated environment. In Riley, R. (Eds.) Manual of simulation in healthcare (pp. 99 -137). Oxford, UK: Oxford University Press Cumin, D., Merry, A. F., Weller, J. M. Standards for simulation. Anesthesia, 2008, 63, 1281-1287.

[14] Sinz, E. 2006 Simulation Conference. Simulation in Healthcare. 2007; 2: 33-38.

[15] Bosworth TL, Haloburo EE, Hetrick C, Patchett K, Thompson MA, Welch M. International partnerships to promote quality care: faculty groundwork, student projects, and outcomes. Journal of Continuing Education in Nursing. 2006; 37: 32-38. PMid:16479847

[16] Levine M. Transforming experiences: Nursing education and international immersion programs. Journal of Professional Nursing. 2009; 25: 159-169. PMid:19450787 http://dx.doi.org/10.1016/j.profnurs.2009.01.001

[17] Ruddock H C, Turner, DS. Developing cultural sensitivity: Nursing students' experiences of a study abroad program. Journal of Advanced Nursing. 2007; 59: 361-369. PMid:17608686 http://dx.doi.org/10.1111/j.1365-2648.2007.04312.x 